\title{
THE METABOLISM OF CORTICOSTERONE IN MAN
}

\author{
By RALPH E. PETERSON * AND CHARLES E. PIERCE * \\ (From the National Institute of Arthritis and Metabolic Diseases, National Institutes of Health, \\ Bethesda, Md.)
}

(Submitted for publication November 5, 1959; accepted December 4, 1959)

Corticosterone was the first biologically active hormone to be isolated from adrenal gland extracts $(1,2)$. Although contributing little to the body pool of adrenocortical steroids in man, it is one of the major adrenocortical secretory products in some animals, e.g., rodents (3). In man the major glucocorticosteroid is cortisol and the major mineralocorticosteroid is probably aldosterone; nevertheless, corticosterone has been identified and measured in human adrenal tissue (4), adrenal gland perfusates (5), adrenal vein blood $(6-8)$, and peripheral blood (9-16). In all of these tissues the corticosterone concentration was found to be lower than that of cortisol, although the concentration of the biologically important aldosterone has been found to be even less than that of the corticosterone $(17,18)$.

Unlike cortisol, little is known about the rates of secretion of corticosterone in the normal subject, or its alteration in disease. This paucity of knowledge stems largely from the fact that there are no readily available quantitative or semiquantitative methods for determining even a single fraction of the metabolites of corticosterone in the urine.

In previous reports we have described studies on the physiological disposition and metabolic fate of cortisol (19) and cortisone (20) in man. This paper describes similar studies with corticosterone using corticosterone, corticosterone-4- $\mathrm{C}^{14}$, and $\mathrm{H}^{3}$ labeled corticosterone. ${ }^{1}$

\footnotetext{
* Present address: Cornell University Medical Center, Department of Medicine, New York 21, N. Y.

${ }^{1}$ In this paper the trivial names of the steroids have been used: cortisol $(11 \beta, 17 \alpha, 21$-trihydroxy-4-pregnene3,20-dione); cortisone (17 $\alpha, 21$-dihydroxy-4-pregnene-3,-

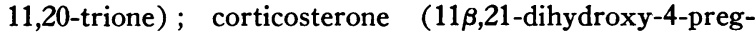
nene-3,20-dione); tetrahydrocortisone $(3 \alpha, 17 \alpha, 21$-trihydroxy-pregnane-11,20-dione) ; tetrahydrocortisol $(3 \alpha, 11 \beta,-$ $17 \alpha, 21$-tetrahydroxy-pregnane,20-one) ; tetrahydrocorticosterone $(3 \alpha, 11 \beta, 21$-trihydroxy-pregnane-20-one $) ; 9 \alpha$ -

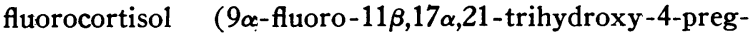
nene-3,20-dione) ; $\Delta^{1}-9 \alpha$-fluorocortisol ( $9 \alpha$-fluoro-11 $\beta, 17 \alpha,-$
}

\section{MATERIALS AND METHODS}

Seventeen normal subjects, one bilaterally adrenalectomized subject, and patients with cirrhosis, myxedema, and thyrotoxicosis were studied.

Corticosterone was prepared for intravenous administration by dissolving 50,100 or $200 \mathrm{mg}$ of the crystalline steroid in 10 to $15 \mathrm{ml}$ ethanol, which was added to 300 $\mathrm{ml}$ sterile 5 per cent dextrose in water. The solution was infused over a period of 10 to 20 minutes. The orally administered corticosterone was suspended in saline or given in a gelatin capsule. Corticosterone-4- $\mathrm{C}^{\mathbf{1 4}}$ $(0.004 \mu \mathrm{c}$ per $\mu \mathrm{g})$ was administered intravenously in trace quantities (100 to $400 \mu \mathrm{g}$ ) in a small volume of 5 per cent ethanol in sterile distilled water over a period of 5 minutes. Corticosterone- $\mathrm{H}^{3}(1.5 \mu \mathrm{c}$ per $\mu \mathrm{g})$ was administered in trace quantities ( 7 to $30 \mu \mathrm{g}$ ) in a small volume of 5 per cent ethanol in sterile distilled water. After injection of the steroids, heparinized blood samples were collected at 20 to 30 minute intervals.

The extraction procedures for the plasma corticosterone were similar to those described previously for cortisol (19). Following the infusion of the pharmacalogical quantities of the steroid, two different methods were used to determine the plasma corticosterone concentration.

Fluorometric assay. Five-tenths $\mathrm{ml}$ plasma was extracted with $5 \mathrm{ml}$ dichloromethane [purified by passage through a column of silica gel (21)]. The plasma was removed by aspiration, and the dichloromethane extract

21-trihydroxy-1,4-pregnene-3,20-dione) ; 11-dehydrotetra-

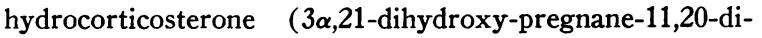
one) ; $3 \alpha$-allotetrahydrocorticosterone $(3 \alpha, 11 \beta, 21$-trihydroxy-allopregnane-20-one) ; 11-dehydroallotetrahydro-

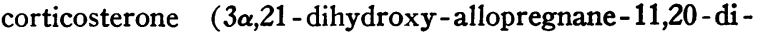
one) ; 11-dehydro-corticosterone (21-hydroxy-4-pregnene3-11,20-trione) ; 11-desoxycortisol (17 $\alpha, 21$-dihydroxy4-pregnene-3,20-dione) ; $20 \alpha$-hydroxycorticosterone (11 ,$20 \alpha, 21$-trihydroxy-4-pregnene-3-one); $20 \beta$-hydroxycorticosterone $(11 \beta, 20 \beta, 21$-trihydroxy-4-pregnene-3-one) ; 11 epicorticosterone (11 $\alpha, 21$-dihydroxy-4-pregnene-3,20-dione) ; allotetrahydrocortisol ( $3 \alpha, 11 \beta, 17 \alpha, 21$-tetrahydroxyallopregnane-20-one); allotetrahydrocortisone $(3 \alpha, 17 \alpha, 21$ trihydroxy-all -pregnane-11, 20-dione) ; $\Delta^{1}-9 \alpha$-fluoro-16 $\alpha$ hydroxycortisol diac (16 2 ,21-diacetoxy-11 $\alpha, 17 \alpha$-dihydroxy$9 \alpha$-fluoro-1,4-pregnene-3,20-dione); $2 \alpha$-methylcortisone (2 $\alpha$-methyl-11 $\beta, 17 \alpha, 21$-trihydroxy-4-pregnene-3,20-dione) ; $20 \beta$-hydroxycortisone $(17 \alpha, 20 \beta, 21$-trihydroxy-4-pregnene3,11-dione). 
washed with $0.5 \mathrm{ml} 0.1 \mathrm{~N} \mathrm{NaOH}$. Each of two $2 \mathrm{ml}$ aliquots of the extract was transferred to a small conical test tube and shaken with $1 \mathrm{ml}$ of a sulfuric acid-ethanol (redistilled ethanol) reagent $(65: 35 \mathrm{vol} / \mathrm{vol})$. The solvent was removed by aspiration and the acid-alcohol reagent transferred to a small cuvet for fluorescence determination in a Farrand fluorometer by a previously described modification (12) of the method of Sweat (22).

Isotope dilution assay. The plasma samples were also assayed for corticosterone by the isotope dilution procedure as previously described (12), except that $5 \mathrm{ml}$ of plasma was used for each determination. Radioactivity measurements were made in a Tri-Carb liquid scintillation spectrometer (Packard Instrument Co.).

Determination of plasma corticosterone $-H^{3}$ and labeled metabolites. The disappearance of $\mathrm{H}^{3}$-labeled corticosterone from the plasma was determined by first adding a known number of counts of corticosterone-4- $\mathrm{C}^{14}$ (500 cpm at an efficiency of 30 per cent) to a known volume of each plasma sample collected after the infusion of the labeled steroid. The plasma was extracted with dichloromethane and the residue chromatographed in a modified Bush-type system (23) (cyclohexane 100: benzene 100 : methanol 100 : water 50 ) for 24 hours at room temperature using unlabeled corticosterone $(20 \mu \mathrm{g})$ as a marker. The corticosterone was then located with ultraviolet light, eluted, and assayed for $\mathrm{C}^{14}$ and $\mathrm{H}^{3}$ in a liquid scintillation spectrometer. The $\mathrm{C}^{14}$ in this case was used to correct for losses of corticosterone- $\mathrm{H}^{3}$ during the extraction, evaporation, chromatography, and elution steps. The mixtures of $\mathrm{C}^{\mathrm{i} 4}$ and $\mathrm{H}^{3}$ were counted by previously described methods (24). The combined plasma "free" corticosterone and its metabolites were measured by direct counts of an aliquot of the dichloromethane extract of the plasma. The plasma radioactive metabolites of corticosterone conjugated with glucuronic acid were determined by a previously described method (19).

Determination of specific activity of labeled plasma corticosterone. Fifteen to $20 \mathrm{ml}$ of heparinized plasma collected serially after injection of corticosterone- $\mathrm{H}^{3}$ was extracted with 7 volumes of dichloromethane. The plasma was removed by aspiration, and the dichloromethane washed successively with $1 / 10$ volume $0.1 \mathrm{~N}$ $\mathrm{NaOH}$ and $1 / 10$ volume of $0.1 \mathrm{M}$ acetic acid. The dichloromethane extract was evaporated to dryness. Twenty $\mu \mathrm{g}$ of 11 -desoxycortisol was added to the residue, and this was applied to Whatman no. 1 filter paper and chromatographed (cyclohexane 100: benzene 100: methanol 100: water 50) for 24 hours. After the chromatography the strip was scanned with ultraviolet light, and the 11-desoxycortisol located. (Corticosterone in 24 hours runs 2 to $3 \mathrm{~cm}$ slower than 11-desoxycortisol in this system.) The 3 to $4 \mathrm{~cm}$ portion of the paper just proximal to 11-desoxycortisol was cut out and the corticosterone eluted with ethanol. The alcohol was evaporated to dryness in a small, conical, glass-stoppered test tube.

The dry residue was acetylated with equal parts of 15 per cent ( $\mathrm{vol} / \mathrm{vol})$ acetic anhydride-1-C $\mathrm{C}^{14}$ (2 mc per mmole) in benzene and in pyridine for 24 hours at room temperature. The unused acetic anhydride was removed by partitioning twice between a small volume of 20 per cent ethanol and dichloromethane. The aqueous layer was removed by aspiration into an alkali trap. After addition of $20 \mu \mathrm{g}$ of corticosterone acetate, the dichloromethane was evaporated to dryness. The residue was chromatographed successively in the following systems: 1) cyclohexane 100 : benzene $50:$ methanol $100:$ water 25,15 hours ; 2) cyclohexane 100 : dioxane $100:$ methanol 50 : water 25,18 hours; and 3) cyclohexane 100 : benzene 50 : methanol 100 : water 25,15 hours. After elution from the second chromatographic purification and prior to the third and final chromatography, the residue was oxidized to 11-dehydrocorticosterone acetate with $0.1 \mathrm{ml} 0.5$ per cent $\mathrm{CrO}_{3}$ in redistilled glacial acetic acid. After exposure to the $\mathrm{CrO}_{3}$ for 1 minute at room temperature, $1 \mathrm{ml}$ of 20 per cent ethanol-water was added and the steroid acetate was extracted with dichloromethane. The dichloromethane was evaporated to dryness and the residue applied to paper for the third chromatographic purification.

The 11-dehydrocorticosterone acetate was eluted into a counting vial, dried, and $5 \mathrm{ml}$ toluene containing 0.4 per cent DPO (diphenyloxazole) and 0.004 per cent POPOP [1,4-bis-2-(5-phenyloxazoly1)-benzene] phosphor added. The samples were assayed for $\mathrm{C}^{14}$ and $\mathrm{H}^{3}$ in a liquid scintillation spectrometer. The calculations of the specific activities have been described previously (24). From a knowledge of the specific activity of the acetic anhydride-1- $\mathrm{C}^{14}$ and the $\mathrm{C}^{14}$ counts in the counting vial, it was possible to determine the micrograms of corticosterone in the vial. From the counts of tritium and the micrograms of corticosterone in the val, the specific activity of the corticosterone was determined. The fractional rate of turnover of corticosterone and the miscible pool size were determined as previously described for cortisol (25).

Comparison of in vivo metabolism of $\mathrm{H}^{3}$ - and $\mathrm{C}^{14}$-labeled corticosterone. A solution of $320 \mu \mathrm{g}$ corticosterone labeled with both $\mathrm{H}^{3}$ and $\mathrm{C}^{14}$ was injected into a normal subject (N. K.) who was receiving a continuous intravenous infusion of corticotropin ( 4 units per hour) for 36 hours. The labeled steroid was given 12 hours after the start of the infusion. Blood samples were collected every 30 minutes for 3 hours. The plasma corticosterone specific activities were determined as previously described (isotope dilution assay utilizing measurements of fluorescence), except that both radioactive carbon and tritium measurements were made. The ratio of specific activities of the carbon and tritium were constant for the 3 hours of the study, thus indicating that the $\mathrm{C}^{14}$ - and $\mathrm{H}^{3}$ labeled corticosterone were probably handled in a similar manner (Figure 1).

The $\mathrm{C}^{14}$ - and $\mathrm{H}^{3}$-labeled urinary metabolites were also assayed in this same subject, and no significant differences were found in the rate of excretion of the administered $\mathrm{C}^{14}$ and $\mathrm{H}^{3}$ in the total, free, and glucuronide-con- 


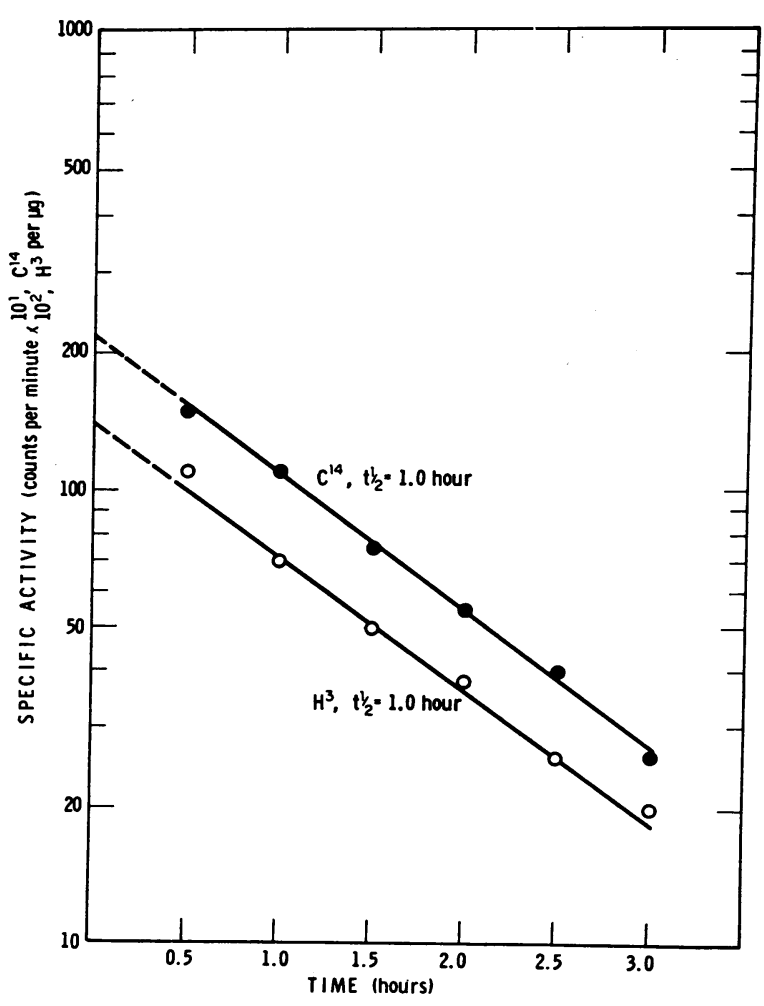

Fig. 1. SPECIFIC ACtivity of CoRTICosterone IN PLASMA FOLLOWING INTRAVENOUS ADMINISTRATION OF $320 \mu \mathrm{G}$ OF CORTICOSTERONE LABELED WITH $\mathrm{H}^{3}$ AND $\mathrm{C}^{14}$, GIVEN DURING INFUSION OF CORTICOTROPIN.

jugated metabolites (18). Studies of the plasma fractions (total, free, and glucuronide) following the infusion of a mixture of $\mathrm{H}^{3}$ - and $\mathrm{C}^{14}$-labeled corticosterone also showed no differences in the $\mathrm{H}^{3}$ to $\mathrm{C}^{14}$ ratios (18). Determinations were made of the $\mathrm{C}^{14}$ and $\mathrm{H}^{3}$ in the corticosterone, tetrahydrocorticosterone, allotetrahydrocorticosterone, and 11-dehydrotetrahydrocorticosterone isolated from the urine. The labeled corticosterone and 11dehydrotetrahydrocorticosterone were diluted with their respective carrier steroids and recrystallized twice, and the $\mathrm{C}^{14}$ and $\mathrm{H}^{3}$ content again determined. It was not possible within the experimental error of the methods for counting the mixtures of $\mathrm{H}^{3}$ and $\mathrm{C}^{14}$ to observe any significant differences in the ratios of tritium to carbon in the urinary corticosterone or the metabolites of corticosterone. The ratio of $\mathrm{H}^{3}$ to $\mathrm{C}^{14}$ in all cases approximated the $\mathrm{H}^{3}$ to $\mathrm{C}^{14}$ ratio in the administered corticosterone.

Daily rate of turnover of corticosterone by assay of specific activity of urinary metabolites. The specific activities of urinary corticosterone, tetrahydro- and allotetrahydrocorticosterone, and 11-dehydrocorticosterone were determined on the 24 hour collections of urine after the infusion of trace quantities of $\mathrm{H}^{3}$-labeled corticosterone $(7$ to $30 \mu \mathrm{g})$, or slightly larger than trace quanti- ties of corticosterone-4-C $\mathrm{C}^{14}$ (100 to $\left.400 \mu \mathrm{g}\right)$. The labeled corticosterone and its metabolites were presumed to be diluted only by the corresponding unlabeled steroid and its metabolites, and the collection of radioactivity in the metabolites was presumed to be nearly complete within the first 24 hours. From a knowledge of the specific activity of the isolated steroid and the quantity and specific activity of the injected steroid, plus a record of the time of the urine collection after administration of the labeled steroid, it was possible to calculate the rate of steroid secretion $(17,18,26,27)$ :

$$
\begin{aligned}
\left(\frac{I_{i}(f)}{I_{0}}-1\right) a \times & \text { no. days } \\
& =\text { micrograms of steroid secreted per day, }
\end{aligned}
$$

where $I_{1}=$ specific activity of :injected steroid; $f=$ ratio molecular weight of injected steroid to molecular weight of steroid metabolite; $\mathrm{I}_{0}=$ specific activity of diluted urinary steroid metabolite; $a=$ micrograms of steroid injected.

The specific activities of urinary steroid metabolites were determined by the following method: one hundred to $200 \mathrm{ml}$ of urine was treated with Sigma bacterial $\beta$-glucuronidase ( 50 units per $\mathrm{ml}$ ) for 24 hours at $37^{\circ} \mathrm{C}$, and the urine was extracted /with 7 volumes of dichloromethane. The dichloromethane was washed with alkali and acetic acid and evaporated to dryness as previously described. The residue was dissolved in a small volume of ethanol, and water added to a concentration of 25 per cent ethanol-water. This was extracted with 5 volumes of petroleum ether. The ether was removed by aspiration, and the aqueous solution extracted with 7 volumes of dichloromethane. The aqueous layer was removed by aspiration and the dichloromethane evaporated to dryness.

The extract was chromatographed in the cyclohexane 100 : benzene 100 : methanol 100 : water 50 system for 20 hours. The tetrahydro metabolites were located by use of a strip counter for detection of radioactivity, or by the aid of added steroid markers visible in ultraviolet light, with running rates close to or identical with the metabolite of interest: corticosterone $27 \mathrm{~cm} ; 3 \alpha$-tetrahydrocorticosterone, $16 \mathrm{~cm} ; \Delta^{1}-9 \alpha$-fluoro-16 $\alpha$-hydrocortisol diac, $16 \mathrm{~cm} ; 3 \alpha$-allotetrahydrocorticosterone, $20 \mathrm{~cm} ; 2 \alpha$ methyl-cortisone, $21 \mathrm{~cm} ; 3 \alpha$,11-dehydrotetrahydrocorticosterone, $25 \mathrm{~cm}$; corticosterone, $27 \mathrm{~cm}$; $3 \alpha, 11$-dehydroallotetrahydrocorticosterone, $31 \mathrm{~cm} ; 11$-desoxycortisol, 30 $\mathrm{cm}$.

After the steroid metabolites were eluted separately, they were acetylated with labeled acetic anhydride $\left[\mathrm{H}^{3}-\right.$ labeled acetic anhydride (100 mc per mmole) was used for the $\mathrm{C}^{14}$-labeled metabolites, and acetic anhydride-1-C $\mathrm{C}^{14}$ ( $5 \mathrm{mc}$ per mmole) for the $\mathrm{H}^{3}$-labeled metabolites]. The labeled acetylated derivatives were purified by paper chromatography in three different systems to remove all traces of contaminating radioactivity: 1) cyclohexane 100 : benzene 25 : methanol 100 : water 10,12 hours; 2) cyclohexane 100 : nitromethane 50 : methanol 50,48 hours; and 3) cyclohexane 100: methanol 100 : water 10, 20 hours. 
Prior to the final chromatography, all of the derivatives were converted to the 11-oxo compounds by mild oxidation with $\mathrm{CrO}_{3}$. The diacetates of the $3 \alpha, 5 \alpha$ (allo) compounds had a slower mobility than the $3 \alpha, 5 \beta$ isomers. ${ }^{2}$

The final purified steroid acetates were assayed for tritium and carbon radioactivity in a liquid scintillation spectrometer. From a knowledge of the specific activity of the labeled acetic anhydride plus the radioactive counts contributed to the final counting sample by the labeled acetoxy groups, it was possible to calculate the quantity of steroid in the counting vial. From the radioactive counts of the second (injected) steroid, plus the micrograms of steroid counted, it was possible to determine the specific activity of the urinary steroid metabolite after dilution by the endogenous steroid. As with all isotope dilution assays, the results were not invalidated by failure to obtain quantitative recoveries through any of the steps of the procedure.

Quantitative determination of urinary metabolites of corticosterone and cortisol. A known aliquot of the 24 hour urine was treated with Sigma bacterial $\beta$-glucuronidase (100 units per $\mathrm{ml}$ urine, $\mathrm{pH}$ 6.2) for 24 hours at $37^{\circ} \mathrm{C}$. The $\mathrm{H}^{3}$-labeled steroid tetrahydro metabolites ${ }^{3}$ were added, and the urine extracted with dichloromethane. This extract was washed with alkali and acetic acid and evaporated to dryness. The residue was partially purified as previously described above. The residue used for the corticosterone metabolites was chromatographed in the cyclohexane 100 : benzene 100 : methanol 100 : water 50 system for 24 hours. The free steroid metabolites were located as described above. The extracts for the cortisol metabolites were chromatographed in the benzene 100 : methanol 50 : water 25 system for 24 hours. The following steroid markers were used: cortisol, 32 $\mathrm{cm}$; $3 \alpha$-tetrahydrocortisol, $16 \mathrm{~cm} ; \Delta^{1}-9 \alpha$-fluorocortisol, $15 \mathrm{~cm} ; 3 \alpha$-allotetrahydrocortisol, $18 \mathrm{~cm} ; 20 \beta$-hydroxycortisone, $20 \mathrm{~cm}$; $3 \alpha$-tetrahydrocortisone, $27 \mathrm{~cm}$; $9 \alpha$ -

2 A more complete description of the chromatography systems will be described in a forthcoming publication. The monoacetate of corticosterone was chromatographed in the three solvent systems described above for determination of specific activity of labeled plasma corticosterone.

${ }^{3} \mathrm{H}^{3}$-labeled cortisol (1.0 $\mu \mathrm{c}$ per $\left.\mu \mathrm{g}\right)$ and corticosterone $(1.5 \mu \mathrm{c}$ per $\mu \mathrm{g})$ were prepared by exposure of $1.5 \mathrm{mg}$ of the dry steroid acetates to $\mathrm{H}^{3}$ gas. The irradiated steroids were purified by paper chromatography (before and after hydrolysis of the acetates) to a constant specific activity. The $3 \alpha, 5 \beta$ tetrahydro $\mathrm{H}^{3}$ compounds were prepared enzymatically from the parent steroids with the soluble dehydrogenase enzymes from rat liver (28), and the $3 \alpha, 5 \alpha$ tetrahydro compounds were prepared from the parent $\mathrm{H}^{3}$ steroids with the particulate enzymes from the livers of thyrotoxic rats (29). Twenty-five to $50 \mathrm{ml}$ of normal urine was sufficient for the cortisol metabolites, whereas 100 to $200 \mathrm{ml}$ was required for the assay of the corticosterone metabolites. Corticosterone-4-C $\mathrm{C}^{* 4}(1.47 \mathrm{mc}$ per mmole) was obtained from the Endocrine Study Section of the National Institutes of Health. fluorocortisol, $26 \mathrm{~cm}$; $3 \alpha$-allotetrahydrocortisone, $31 \mathrm{~cm}$; cortisol, $32 \mathrm{~cm}$.

After chromatography the free compounds were acetylated with labeled acetic anhydride- $1-\mathrm{C}^{14}$ (5 mc per mmole for corticosterone metabolites and $1.0 \mathrm{mc}$ per mmole for cortisol metabolites) and the derivatives chromatographed in three different solvent systems. The corticosterone metabolites were chromatographed in the three systems described above, and the cortisol metabolites in the following three solvent systems: 1) cyclohexane 100: benzene 25 : methanol 100 : water 10,24 hours; 2) cyclohexane 100 : dioxane $25:$ methanol 100 : water 25,48 hours; 3) cyclohexane $100:$ benzene $25:$ methanol 100 : water 10 , 24 hours.

The monoacetate of cortisol was chromatographed in the following three systems: 1) cyclohexane 50 : benzene 100: methanol 100: water 20, 12 hours; 2) cyclohexane 100 : dioxane 100 : methanol 50 : water 25,30 hours; 3 ) carbon tetrachloride 100: methanol 100 : water 25,15 hours.

With all steroids $\mathrm{CrO}_{3}$ oxidation preceded the third chromatography. After the final chromatography, the eluted steroids were assayed for $\mathrm{C}^{14}$ and $\mathrm{H}^{3}$ in the liquid scintillation spectrometer, and the concentrations of urinary steroids were determined as previously described (24).

Determination of labeled urinary metabolites. The labeled urinary and biliary metabolites of corticosterone$4-\mathrm{C}^{14}$ were measured by previously described methods $(19,20)$, except that with the corticosterone- $\mathrm{H}^{3}$ and some of the corticosterone-4- $\mathrm{C}^{14}$ studies the radioactive measurements were made with a liquid scintillation spectrometer. A small aliquot of urine $(0.1$ to $0.5 \mathrm{ml})$ was added directly to $10 \mathrm{ml}$ toluene, phosphor, and enough ethanol to make the mixture miscible (2 to $6 \mathrm{ml}$ ). A correction for loss of efficiency due to "quenching" was made by utilizing a double isotope differential dilution technique (30).

\section{RESULTS}

Rate of disappearance of corticosterone and "corticosterone-like" material from the plasma after intravenous administration. When the serial concentrations of sulfuric acid-induced fluorescent material in the dichloromethane extracts of plasma after the infusion of corticosterone were plotted against time on semilogarithmic paper, a linear decline in plasma concentration was noted (Figure 2 ). In some of the subjects this first order decline in plasma concentration did not begin until 30 to 60 minutes after the end of the infusion. The decline in plasma concentration during the 30 to 60 minutes after the end of the infusion was rapid and did not represent a single exponential. When corticosterone was assayed by the more selective isotope dilution method, the nonlinear 
nature of the initial concentration curve was also observed. With both the sulfuric acid-induced fluorescence and the isotope dilution assay the slopes of the slower linear curve of declining steroid concentrations were similar. However, in all instances the plasma levels of corticosterone as measured with the more specific isotope dilution assay were always 10 to 20 per cent lower than the levels obtained with the less selective fluorometric assay.

In one normal subject $0.4,50,100$ and $200 \mathrm{mg}$ corticosterone were infused on separate occasions (Figure 3). The slopes of the slower curve of declining steroid concentrations were similar at the three larger dosage levels. The similar rates for metabolism of these three different concentrations of corticosterone and the first order nature of the decline in plasma concentration indicated that the rate of metabolism of infused corticosterone was proportional to concentration. Also, corticosterone and its sulfuric acid-induced fluorescent metabolites were metabolized at a similar rate. These rates of metabolism were conveniently expressed as biological half-times. Figure

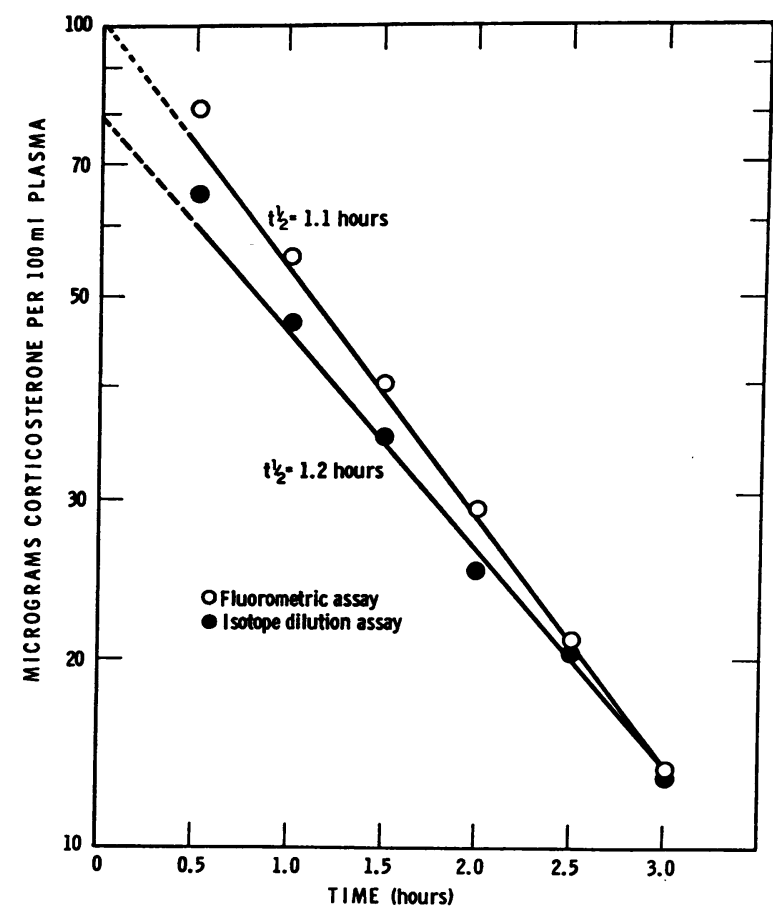

Fig. 2. Disappearance of corticosterone From PLASMA FOLLOWING INTRAVENOUS ADMINISTRATION OF 100 MG OF CORTICOSTERONE.

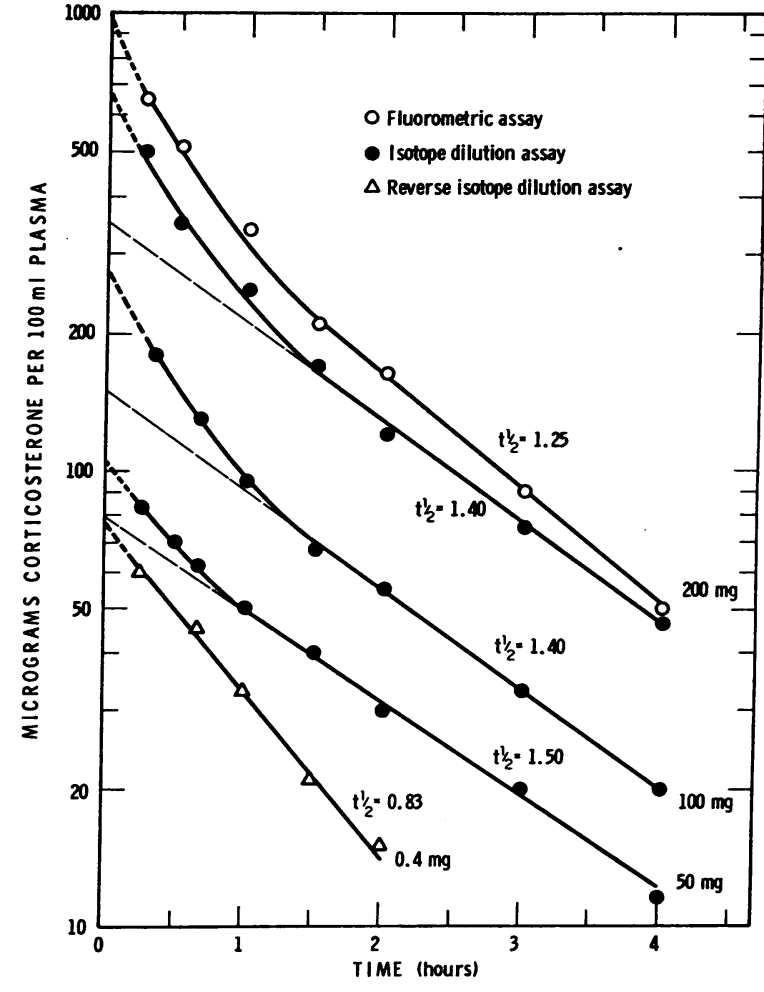

Fig. 3. Disappearance oF CORTICOSTERONE FROM Plasma following intravenous administration. The 0.4 MG DOSE OF STEROID WAS GIVEN AS CORTICOSTERONE4-C ${ }^{14}$.

4 shows the comparative rates of metabolism of corticosterone in normal subjects, in patients with cirrhosis, myxedema, and thyrotoxicosis, and in normal subjects treated with estrogens.

In the normal subjects the biological half-times ranged from 0.9 to 1.6 hours with a mean of 1.27 hours $\pm 0.3 \mathrm{SD}$. A more rapid rate of metabolism was observed in three patients with thyrotoxicosis. The patients with cirrhosis and myxedema showed only a slightly delayed capacity for metabolism of infused corticosterone. Normal subjects given estrogens also showed a delayed metabolism.

Disappearance of radioactive corticosterone from the plasma. Intravenously infused tracer quantities of $\mathrm{H}^{3}$-labeled corticosterone disappeared at a constant first order rate (Figures 3 and 5). However, the rates of disappearance of the trace and the pharmacological quantities were different. The larger amounts were metabolized at a slower rate. This would not appear to be attributable to a difference in the rate of metabolism of the $\mathrm{H}^{3}$ and $\mathrm{C}^{14}$-labeled, and unlabeled steroid. In Figure 


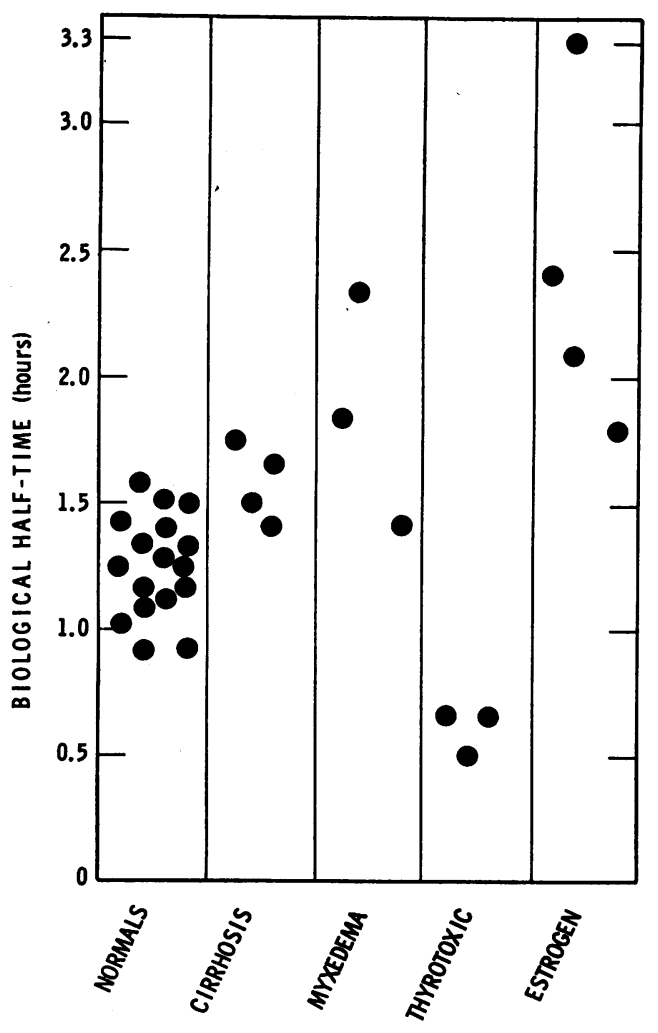

Fig. 4. Biological half-times of intravenously ADMINISTERED CORTICOSTERONE (100 MG). The biological half-times were determined by fluorometric assay of the plasma samples.

5 the plasma levels, in both studies on the same subject, represent a measure of the $\mathrm{H}^{3}$ label on the corticosterone. With the pharmacological dose, the plasma steroid concentrations were also measured by the fluorometric method and a halftime of 1.2 hours was found. The more rapid appearance in the plasma of the metabolites of corticosterone conjugated with glucuronic acid indicated that the trace dose disappeared from the plasma (metabolism) at a more rapid rate. As the corticosterone disappeared from the plasma, conjugated derivatives hydrolyzed with $\beta$-glucuronidase appeared and reached a maximum at 30 to 60 minutes, at which time the free and conjugated fractions were of similar magnitude. Thereafter the conjugated fraction exceeded the free fraction. A large portion of the free and labeled steroids in the plasma following the injection of labeled corticosterone was not corticosterone. The labeled metabolites of cortico- sterone disappeared at a more rapid rate than corticosterone.

Excretion of corticosterone and its metabolites. Figure 6 shows the cumulative urinary and biliary excretion of labeled corticosterone following the intravenous administration of a tracer quantity of corticosterone-4- $\mathrm{C}^{\mathbf{1 4}}$ to a patient with a biliary cannula. The feces collected for three days following the injection of the labeled steroid did not contain any $\mathrm{C}^{14}$. The total quantity of metabolites appearing in the bile over a period of 24 hours was 11 per cent. Direct dichloromethane extraction of the bile recovered only a trace of radioactivity, and thus none of the biliary metabolites represented unaltered corticosterone.

Sixty-six per cent of the injected steroid was excreted in the urine in the first 24 hours and 80

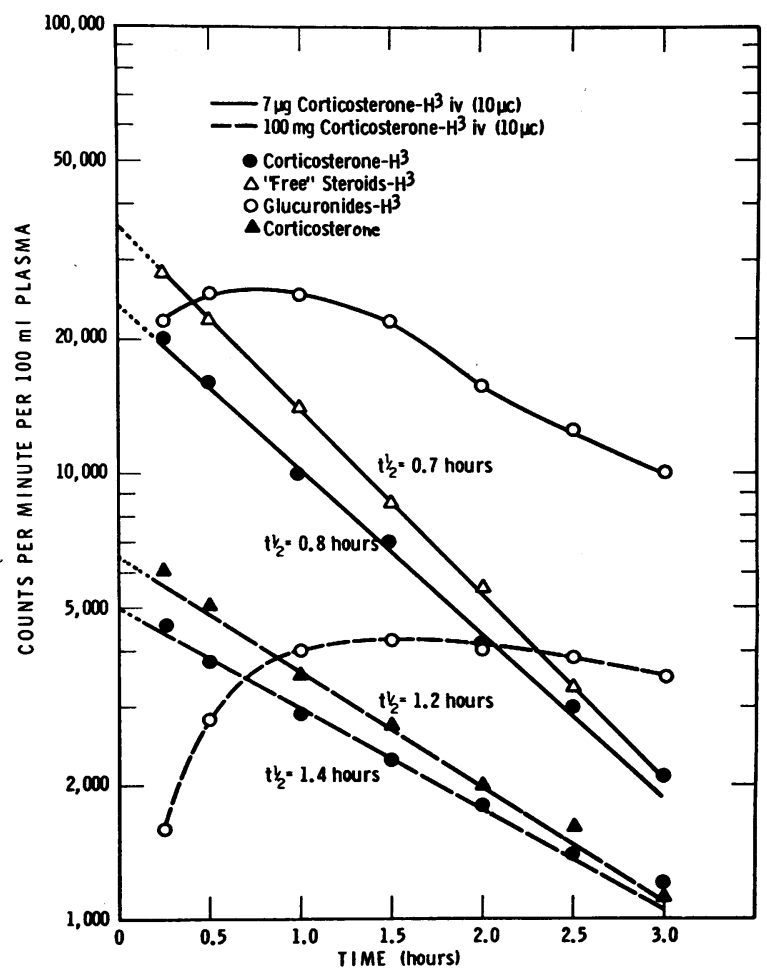

Fig. 5. Corticosterone AND GLUCURONIDE-CONJUGated STEROID METABOLITES OF CORTICOSTERONE IN PLASMA AFTER INTRAVENOUS ADMINISTRATION OF CORTICOSTERONE- ${ }^{3}$. $\triangle$ "Free" steroids- $\mathrm{H}^{3}$ represents the fraction of radioactive metabolites extractable with dichloromethane and $\bigcirc$ glucuronides $-\mathrm{H}^{3}$ represents the fraction of $\mathrm{H}^{3}$-labeled radioactive metabolites extractable with dichloromethane after prior incubation of plasma with $\beta$-glucuronidase. $\Delta$ Corticosterone was measured by direct fluorometric assay of the dichloromethane extract of the plasma. 


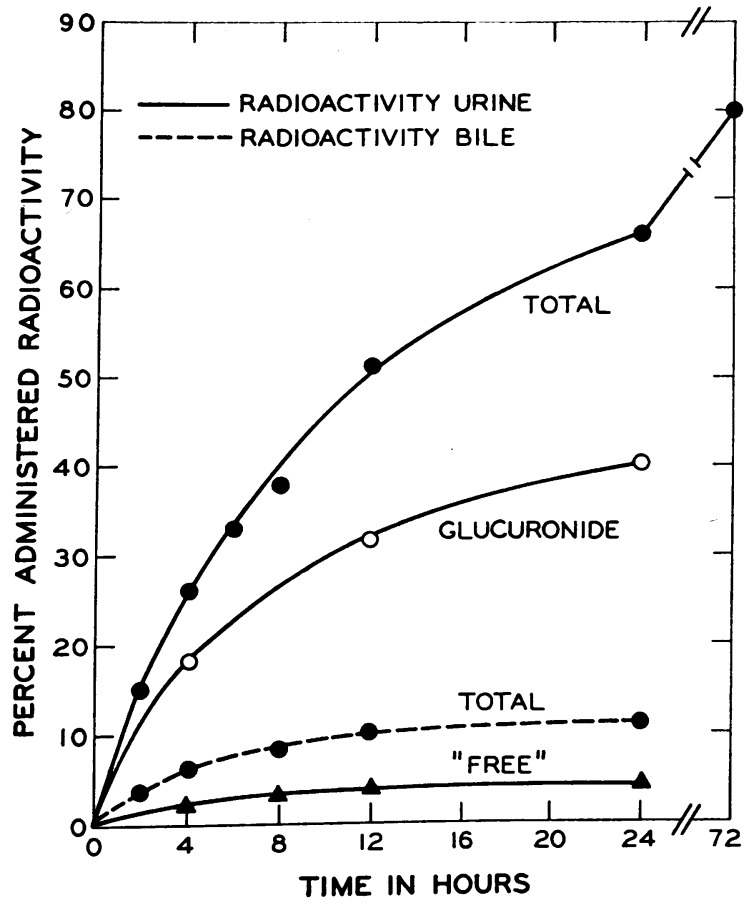

Fig. 6. Cumulative uRinary and Biliary EXCReTION OF RADIOACTIVITY FOLLOWING INFUSION OF $3 \mu \mathrm{C}$ OF CORTICOSTERONE-4-C $\mathrm{C}^{14}$.

per cent in 72 hours. By the fourth day no labeled urinary products could be demonstrated. Forty per cent of the infused steroid could be extracted from the first 24 hour urine collection after hydrolysis with $\beta$-glucuronidase, whereas only 3.5 per cent was extracted directly with dichloromethane. Incubation of the urine at $\mathrm{pH}$ 1.0 at $24^{\circ} \mathrm{C}$ for 24 hours did not make any of the labeled steroids extractable with dichloromethane. Nine per cent of the infused steroid was not accounted for in either the urine or the bile.

On other studies in normal subjects in which only the urinary metabolites were measured similar results were obtained (Table I). Most of the radioactive metabolites appeared in the first 24 hours. However, no more than 90 per cent of the administered steroid could be recovered in the 72 hour urine. Three studies in which fractional urine collections were made showed that onehalf of the radioactivity excreted during the first day appeared in the urine in 2.5 to 3.2 hours. From 2 to 5.5 per cent of the labeled urinary steroid metabolites were extracted with dichloromethane without prior hydrolysis, whereas following $\beta$-glucuronidase hydrolysis and dichloromethane extraction of the urine, 40 to 60 per cent of the excreted radioactive material was recovered.

Urinary metabolites of corticosterone. The free steroid metabolites of corticosterone made up a very small fraction of the total urinary metabolites, and corticosterone accounted for only a trace (less than 0.5 per cent) of the total quantity of steroid injected. $\beta$-Glucuronidase hydrolysis of the urine released appreciable quantities of the tetrahydro metabolites of corticosterone. Table II shows the quantities of corticosterone and the tetrahydro and allotetrahydro metabolites of corticosterone in the 24 hour urine of a normal subject, and in the same normal subject given corticotropin, and $100 \mathrm{mg}$ corticosterone. The data on the tetrahydro metabolites of cortisol are shown

TABLE I

Urinary excretion of labeled radiometabolites following administration of corticosterone-4-C ${ }^{14}$ or corticosterone- $\mathrm{H}^{3}$

\begin{tabular}{|c|c|c|c|c|c|c|}
\hline \multirow[b]{2}{*}{ Subject } & \multirow[b]{2}{*}{ Dose } & \multirow[b]{2}{*}{$\% 24 \mathrm{hrs}$} & \multirow{2}{*}{$\% 72 \mathrm{hrs}$} & \multirow[b]{2}{*}{$T_{\frac{1}{2}}$} & \multicolumn{2}{|c|}{$\%$ Total excreted $24 \mathrm{hrs}$} \\
\hline & & & & & Free & Glucuronide \\
\hline $\begin{array}{l}\text { T.R. i.v. } \\
\text { T.R. i.v. } \\
\text { T.R. i.v. } \\
\text { T.R. p.o. } \\
\text { J.B. i.v. } \\
\text { J.B. p.o. } \\
\text { J.B. p.o. } \\
\text { M.P. i.v. } \\
\text { N.K. i.v. }\end{array}$ & $\begin{array}{l}200 \mu \mathrm{g} \\
100 \mathrm{mg} \\
200 \mu \mathrm{g} \\
100 \mathrm{mg} \\
200 \mu \mathrm{g} \\
200 \mu \mathrm{g}^{*} \\
100 \mathrm{mg}^{*} \\
200 \mu \mathrm{g} \mathrm{H}^{3} \\
320 \mu \mathrm{g} \dagger\end{array}$ & $\begin{array}{l}70 \\
60 \\
70 \\
58 \\
66 \\
70 \\
30 \\
81 \\
70(70)\end{array}$ & $\begin{array}{l}92 \\
72 \\
84 \\
68 \\
80 \\
\\
45 \\
90\end{array}$ & $\begin{array}{l}2.6 \\
3.6 \\
2.9\end{array}$ & $\begin{array}{l}5.5 \\
3.0 \\
3.1 \\
3.0 \\
3.0 \\
3.5 \\
2.0 \\
2.0 \\
2.5(3.0)\end{array}$ & $\begin{array}{l}60 \\
53 \\
45 \\
45 \\
60 \\
50 \\
40 \\
55 \\
48(50)\end{array}$ \\
\hline
\end{tabular}

* Administered as the acetate

† Homogenous solution of a mixture of $\mathrm{H}^{3}$ and $\mathrm{C}^{14}$ labeled corticosterone. Figures in parentheses represent fraction of urine metabolites labeled with $\mathrm{H}^{3}$. This subject received a continuous infusion of corticotropin (4 units/hr) throughout the period of study. 
TABLE II

Urinary excretion of metabolites of corticosterone and cortisol and rates of secretion $(m g /$ day) *

\begin{tabular}{|c|c|c|c|c|c|c|c|c|c|}
\hline & \multirow[b]{2}{*}{ D.B. } & \multicolumn{3}{|c|}{ T.R. } & & \multirow[b]{2}{*}{ D.B. } & \multicolumn{3}{|c|}{ N.K. } \\
\hline & & Control & ACTH† & $\mathrm{F} \ddagger$ & & & Control & ACTH & $\mathrm{B} \ddagger$ \\
\hline F & 0.04 & 0.044 & 2.0 & 1.5 & B & 0.005 & 0.002 & 0.31 & 1.0 \\
\hline THE & 3.30 & 1.85 & 10 & 10 & THA & 0.06 & 0.16 & 1.0 & 3.0 \\
\hline $\mathrm{THF}$ & 2.00 & 1.30 & 22 & 10 & $\mathrm{THB}$ & 0.12 & 0.27 & 4.0 & 6.1 \\
\hline Allo-THE & 0.08 & 0.03 & 0.5 & 0.5 & Allo-THA & 0.02 & 0.01 & 0.1 . & 0.5 \\
\hline Allo-THF & 0.80 & 0.50 & 12 & 5.2 & Allo-THB & 0.30 & 0.30 & 5.2 & 9.0 \\
\hline Total & 6.20 & 3.68 & 46.5 & 24.2 & Total & 0.50 & 0.74 & 10.6 & 19.6 \\
\hline $\mathrm{P}-\mathrm{S} \S$ & 7.0 & 4.4 & 46 & 22 & & & & & \\
\hline Turnover & 15.6 & 12.5 & 154 & 102 & Turnover & 1.3 & 2.3 & 41 & 99 \\
\hline
\end{tabular}

* $\mathrm{THE}=$ tetrahydrocortisone, $\mathrm{THA}=$ tetrahydro-11-dehydrocorticosterone, $\mathrm{THF}=$ tetrahydrocortisol, $\mathrm{THB}=$ tetrahydrocorticosterone, Allo-THE = allotetrahydrocortisone, Allo-THA = allotetrahydro-11-dehydrocorticosterone, Allo-THF = allotetrahydrocortisol, Allo-THB = allotetrahydrocorticosterone.

$\dagger$ ACTH denotes continuous intravenous infusion of corticotropin ( 4 units $/ \mathrm{hr}$ ) for 36 hours. The assays were made on the urine collected from the twelf th to the thirty-sixth hour.

$\ddagger$ Cortisol or corticosterone, $100 \mathrm{mg}$ i.v.

$\S$ P-S denotes urine corticoid assay (phenylhydrazine reacting chromogens after glucuronidase hydrolysis).

for comparison. Also, in these same subjects the rates of turnover of cortisol and corticosterone are listed.

Rate of turnover of corticosterone. After the injection of corticosterone- $\mathrm{H}^{3}$, serial determination of specific activity (counts per minute per microgram) of plasma corticosterone demonstrated a rapid initial fall in specific activity. Except for a brief period ( 0 to 20 minutes) following injection of the tracer, essentially linear relationships were secured when the isotope content of the plasma corticosterone was plotted against time on semilogarithmic coordinates. The decline in isotopic concentration at any time was proportional to the isotopic concentration at that moment (Figure 1). From the intercepts of the plots, the specific activity of the corticosterone at the moment of mixing at time zero after injection was calculated. From this value and a knowledge of the quantity ( 7 to $30 \mu \mathrm{g}$ ) and specific activity $(1.5 \mu \mathrm{c}$ per $\mu \mathrm{g})$ of the injected tracer, the magnitude of the miscible pool was calculated. In normal subjects the mean value for the miscible pool was $0.3 \mathrm{mg}$ with a range of 0.20 to $0.40 \mathrm{mg}$ (Table III). In normal subjects studied during the 8 to 12 hours of a continuous 48 hour intravenous infusion of corticotropin the pool size ranged from 1.5 to $3.5 \mathrm{mg}$.

From the curve of declining isotopic concentration $T_{1 / 2}$ was determined, and the slope of the curve, $\mathrm{k}$, was calculated from the equation, $\mathrm{k}=$ $\log 2 / \mathrm{T}_{1 / 2}$. The quantity of corticosterone turned over per hour was calculated from the product of $\mathrm{k}$ and the pool size, and expressed as milligrams of corticosterone turned over per hour. The mean corticosterone turnover rate was 0.7 pool per hour, or $0.18 \mathrm{mg}$ per hour, with a range of 0.14 to $0.34 \mathrm{mg}$ per hour.

In the normal subjects given corticotropin the fractional turnover per hour was much the same as that in the normal subjects not given corticotropin; however, the pool size was increased nearly tenfold so that the rate of turnover of corticosterone was markedly increased. In the one subject in which a turnover rate study was carried out with a mixture of $\mathrm{H}^{3}$ - and $\mathrm{C}^{14}$-labeled corticosterone, the results with each isotope were comparable. Serial determination of plasma corticosterone specific activities after injection of $200 \mu \mathrm{g}$ of corticosterone-4-C ${ }^{14}(0.004 \mu \mathrm{c}$ per $\mu \mathrm{g})$ showed a less steep slope than that with the trace quantities of $\mathrm{H}^{3}$-labeled corticosterone. Since the rapidly exchangeable pool of corticosterone was demonstrated to be only 0.2 to $0.4 \mathrm{mg}$, it was apparent that this amount of injected corticosterone4-C ${ }^{14}$ equaled the pool size. Attempts to inject less than $200 \mu \mathrm{g}$ met with failure because plasma radioactivity was insufficient for assay.

When the fraction of corticosterone turned over per hour was extrapolated to daily turnover by multiplying by 24 , the daily rates of turnover were calculated to be more than twice the values calculated from the turnover rate method utilizing the specific activity of one or more of the urinary metabolites of corticosterone, except for the subjects receiving corticotropin. With the latter 
method the daily rate of turnover was 1.5 to 4.0 $\mathrm{mg}$ with a mean of $2.3 \mathrm{mg}$ (Table III). There were no marked differences in the results using $\mathrm{H}^{3}-$ and $\mathrm{C}^{14}$-labeled corticosterone. However, with the latter, larger amounts of steroid (200 to $300 \mu \mathrm{g}$ ) were injected. In the few instances in which allotetrahydrocorticosterone or 11-dehydrotetrahydrocorticosterone were isolated in addition to tetrahydrocorticosterone, there were no significant differences in the isotopic content. In some of these same subjects corticosterone was determined and its specific activity found to be 30 to 50 per cent higher than that found in the tetrahydro compounds. In the subjects receiving corticotropin, the calculated daily turnover rates by both methods were approximately the same.

As a means of eyaluating the method utilizing specific activity measurements of urinary metabolites of the labeled steroid and also the stability of the $\mathrm{H}^{3}$ label, studies were carried out on a bilaterally adrenalectomized subject maintained on $\Delta^{1}-9 \alpha$-fluorocortisol for the duration of the studies. The corticosterone- $\mathrm{H}^{3}$ isolated from the urine collected only during the eight hours following infusion had essentially the same specific activity as the injected steroid. Thirty $\mu \mathrm{g}$ of corticosterone- $\mathrm{H}^{3}$ plus $100 \mathrm{mg}$ unlabeled corticosterone were infused into this same patient. In this study three of the tetrahydro metabolites were isolated from the 24 hour urine collection, and the calculated dilution of the administered labeled steroid closely approximated the expected value.

Absorption of corticosterone. Following the oral administration of corticosterone as the free alcohol, peak plasma corticosterone levels of 25 to $50 \mu \mathrm{g}$ per $100 \mathrm{ml}$ were usually reached at one hour, and after six hours the plasma level had returned to the baseline control value. Figure 7 shows the results of one such study in a normal fasted subject. Data are also shown for the

TABLE III

Miscible pool and rate of turnover of corticosterone*

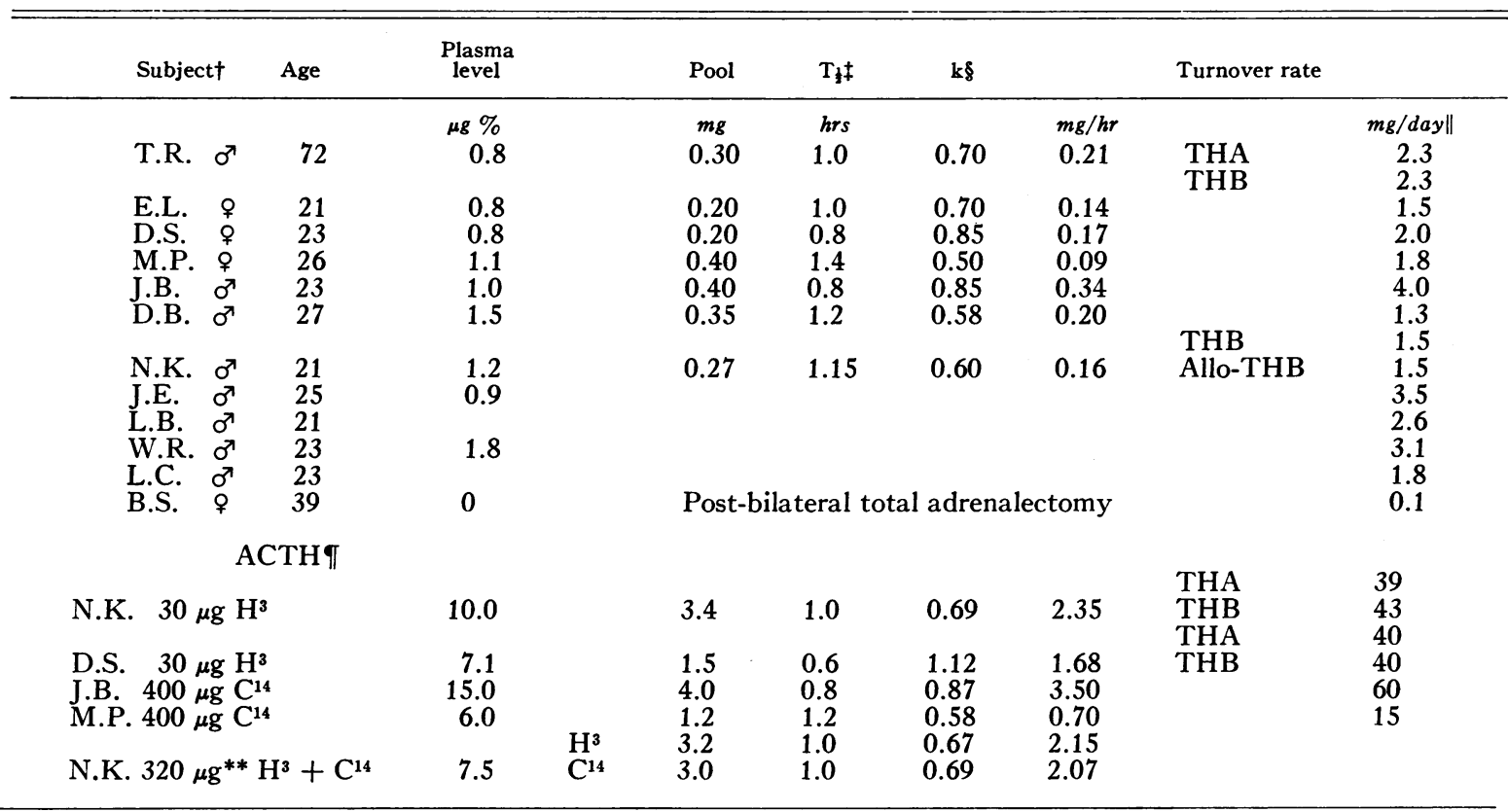

* For abbreviations, see the first footnote to Table II.

† Subjects J.E., L.B., W.R., L.C. and B.S. received 200 to $300 \mu \mathrm{g}$ of corticosterone-4-C ${ }^{14}$ intravenously.

$\ddagger T_{\xi}=$ time for specific activity of corticosterone to be reduced to one-half.

$\$ \mathrm{k}=$ Fraction of pool replaced per hour.

II Based on specific activity of urinary tetrahydrocorticosterone, allotetrahydrocorticosterone, or 11-dehydrotetrahydrocorticosterone.

I ACTH = continuous intravenous infusion of corticotropin (4 units/hr) for 36 hours; labeled corticosterone injected at twelf th hour.

${ }^{* *} \mathrm{~A}$ homogeneous solution of a mixture of $\mathrm{C}^{14}$ - and $\mathrm{H}^{3}$-labeled corticosterone was injected at twelf th hour of infusion of corticotropin. 


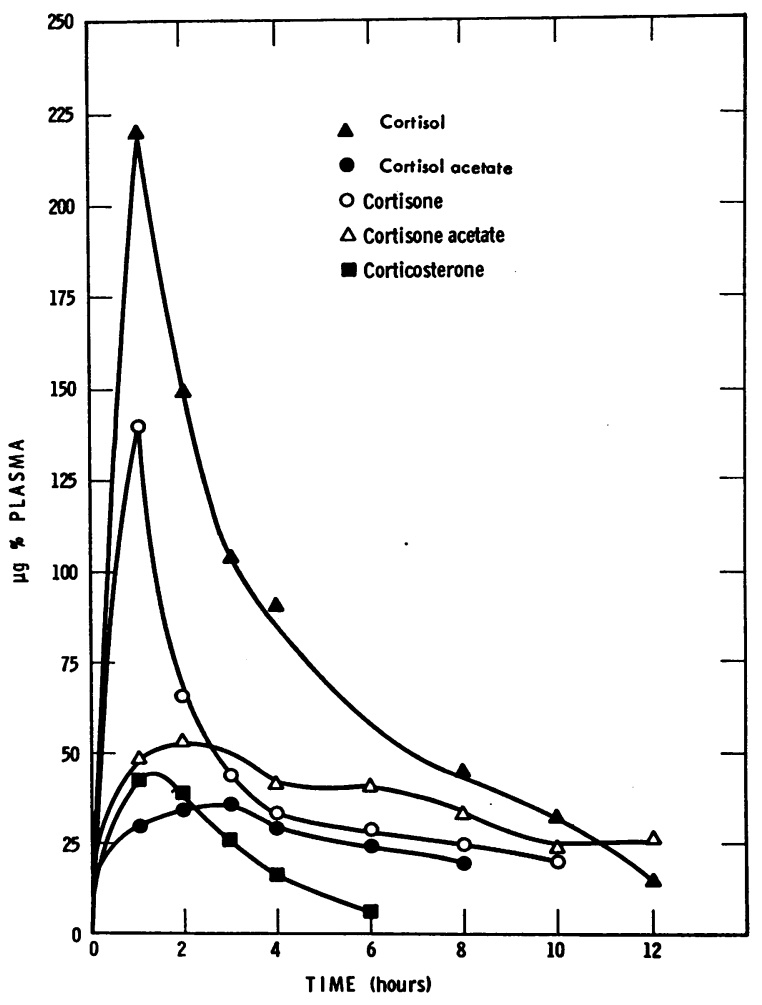

Fig. 7. Comparative plasma Steroid levels folLOWING ORAL ADMINISTRATION OF 200 MG OF STEROIDS. Cortisol AND CORTISOL ACETATE WERE DETERMined AS PHENYLHYDRAZINE-REACTING CHROMOGENS. The steroid levels after cortisone and cortisone acetate represent cortisol as determined by the isotope dilution method. Corticosterone was determined by the isotope dilution method.

plasma levels of cortisol after the administration of cortisol and cortisone and their acetates. Following the administration of $200 \mathrm{mg}$ of corticosterone acetate orally to this same subject, no increase in free corticosterone could be demonstrated in the plasma.

\section{DISCUSSION}

A wide range of pharmacological doses of infused corticosterone, like cortisol, disappeared rapidly from the plasma at a rate proportional to concentration. However, in the normal subjects corticosterone disappeared from the plasma at a slightly more rapid rate, with a biological halftime of 1.27 hours as compared to 1.83 hours for comparable doses of cortisol (19). The use of the modification (12) of the selective sulfuric acid-induced fluorescence assay of Sweat (22) made the measurements of the corticosterone con- centrations in the plasma after infusion of corticosterone relatively simple. Under the conditions of the study this assay proved to be relatively specific. Its validity was evaluated by the use of the more selective isotope dilution assay (12), which usually yielded slightly lower plasma corticosterone levels and a slightly longer biological half-time for infused corticosterone. These differences probably indicated that some of the metabolites of corticosterone gave a moderate fluorescence and were metabolized more rapidly than corticosterone. The $20 \alpha$ and $20 \beta$ reduced stereoisomers of corticosterone are known to be metabolites of corticosterone (31), and with the fluorescence assay they yield approximately one-third the fluorescent intensity of corticosterone (12). In one normal subject given $.50 \mathrm{mg}$ of the $20 \beta$ reduced metabolite of corticosterone, the infused steroid disappeared from the plasma $\left(T_{1 / 2}=0.9\right.$ hour as determined by the fluorescence assay) more rapidly than corticosterone $\left(T_{1 / 2}=1.3\right.$ hours).

One difference between the curves of plasma steroid concentrations of the cortisol and corticosterone was that in the case of the latter the curve in some instances did not become linear until 30 to 90 minutes after the midpoint of the infusion, whereas with the former or with cortisone the curve was usually linear within 20 to 30 minutes $(19,20)$. This was true for both the fluorescence and the isotope dilution methods of assay, was characteristic of only a few individuals, and was not a function of the larger doses of administered corticosterone $(50,100$ or $200 \mathrm{mg})$. This phenomenon was, however, shown to be dosedependent, because with the rapid infusion of trace doses of either $\mathrm{H}^{3}-(7$ to $30 \mu \mathrm{g})$ or $\mathrm{C}^{14}-(200$ to $400 \mu \mathrm{g}$ ) labeled corticosterone, the decline in concentration of labeled corticosterone was always linear within 20 minutes.

In addition to the variations, in the nature of the curve of plasma corticosterone after trace and pharmacological doses, it was also noted that the slopes of the linear portions of the concentration curves were different at the two dose levels. With the trace dose the slope was steeper and thus yielded a shorter biological half-time. This was not found to be due to an altered metabolism of the labeled steroid. With $100 \mathrm{mg}$ of labeled corticosterone the fluorometric assay showed a slope 
similar to that obtained with the radioactive assay. In addition, the more rapid appearance and the higher plasma level of metabolites conjugated as glucuronides after the trace dose revealed another significant difference in the metabolism of corticosterone at different dose levels. Finally, determinations of the "apparent volume of distribution" of the labeled corticosterone at these two dosage levels also demonstrated a significant difference in the distribution of the infused labeled steroid (trace dose, 12 to $40 \mathrm{~L}$; pharmacological dose, 60 to $90 \mathrm{~L}$ ).

Except for the disparity in the initial portion of the curve of the declining corticosterone concentration at the two dosage levels, these same differences were noted with trace and pharmacological doses of cortisol (18). It seems likely that differences in the fraction of nonprotein-bound and protein-bound steroid at physiological (trace) and pharmacological levels may explain these discrepancies. On the basis of the recent reports on the binding of cortisol (32-36) and corticosterone $(33-35,37)$ to plasma proteins, it is evident that when a trace dose of the steroid is infused, close to 100 per cent of the circulating plasma steroid is protein-bound, whereas with pharmacological doses only 70 to 80 per cent is protein-bound. After the infusion of 20 to 200 $\mathrm{mg}$ of steroid, plasma steroid levels may range from 50 to $200 \mu \mathrm{g}$ per $100 \mathrm{ml}$. Thus a larger fraction of nonprotein-bound steroid is available for diffusion into the extravascular space, and equilibration between plasma and the extravascular space may not be approximated rapidly. Under these circumstances the plasma concentration may not be expressed as a constant first order function but rather as a series of exponential terms in which the exponents are functions of the rate constants, for enzymatic transformation by the liver, diffusion into the extravascular space, and re-entry into the plasma. In the absence of significant excretion, even though the rate of decline in plasma concentration represents a first order process, the rate of disappearance of the steroid, especially after infusion of pharmacological quantities, may not always represent a reliable index of the rate of metabolism of endogenous steroid at physiological levels.

It has previously been reported that the chloroform-soluble radioactive metabolites of cortico-
sterone-4-C $\mathrm{C}^{14}$ injected in trace amounts disappeared more rapidly from the plasma than the radioactive metabolites of cortisol-4- $\mathrm{C}^{14}(17,38)$. Also, the peak of the radioactivity of the glucuronide fraction in the plasma reached a maximum more rapidly. In one normal subject, two of the metabolites of corticosterone ( $20 \beta$-hydroxycorticosterone and 11-dehydrotetrahydrocorticosterone) and the $11 \alpha$ epimer of corticosterone were metabolized more rapidly than corticosterone. (20 $\beta$-Hydroxycorticosterone and $11 \alpha$-hydroxycorticosterone were assayed by the fluorescence method, and 11-dehydrotetrahydrocorticosterone by the double isotope dilution derivative assay.) Patients with liver disease showed no marked impairment in their capacity to metabolize corticosterone, whereas cortisol metabolism was significantly impaired $(18,39,40)$. Patients with myxedema and thyrotoxicosis were shown to have an altered metabolism of cortisol $(18,41,42)$, and a similarly altered corticosterone metabolism. Normal subjects treated with estrogens showed a delayed disappearance of both cortisol and corticosterone from the plasma (43). This has been related to alterations in concentration of the steroidbinding proteins after administration of estrogens $(43,44)$.

The major route of excretion of labeled metabolites of corticosterone, like that of cortisol and cortisone, was via the urine. Seventy to 90 per cent of the administered dose could be accounted for in the urine within three days. The cumulative rate of excretion of the labeled steroid metabolites was also similar for these three steroids$\mathrm{T}_{1 / 2}=2.5$ to 4 hours. Only a small fraction of the metabolites of corticosterone was excreted into the gastrointestinal tract via the bile. Only 3 to 5 per cent of the administered steroid was excreted in the urine as radiometabolites directly extractable with dichloromethane, and less than 0.5 per cent of the administered corticosterone was recoverable as unaltered corticosterone. By paper chromatography the direct dichloromethane extracts of urines collected after infusions of 200 $\mathrm{mg}$ of corticosterone were found to contain trace amounts of the $20 \alpha$ and $20 \beta$ hydroxy metabolites of corticosterone. ${ }^{4}$ These findings were based on

4 We are indebted to Dr. M. Darrach for a small supply of $20 \alpha$-hydroxycorticosterone. 
a comparison of the rates of migration of the authentic pure compounds, and by conversion of the steroids to the diacetates and comparison of their chromatographic behavior with that of the authentic derivatives. These two substances isolated from the urine also gave negative reactions with the phenylhydrazine and alkaline blue tetrazolium reagents. Both compounds also gave the alkaline and sulfuric acid fluorescence reactions. Glucuronidase hydrolysis released radiometabolites equivalent to 40 to 60 per cent of the administered steroid. Incubation of the urine at room temperature for 24 hours at $\mathrm{pH} 1$ did not release any radiometabolites. These results are in agreement with the previous data reported for cortisol (19, $45-47)$, cortisone (20), and corticosterone (17, 38,48 ).

Following the intravenous or oral administration of trace $(200 \mu \mathrm{g})$ amounts of labeled corticosterone, comparable amounts of labeled metabolites were present in the urine within 24 hours. However, following the oral administration of 100 to $200 \mathrm{mg}$ of the labeled steroid, a smaller fraction of the urinary metabolites appeared within 24 hours, and after feeding $100 \mathrm{mg}$ of labeled corticosterone acetate, even less appeared in the 24 hour urine. These data are at variance with those on cortisol and cortisone, which indicated that after administration of the free alcohols of the steroids in trace or larger amounts the recovery of the radiometabolites in the urine was not appreciably altered $(19,20,48)$. With cortisone acetate the oral absorption of trace and large doses also gave similar results. With trace doses of cortisol, cortisone and corticosterone and with their acetates, oral and intravenous administration gave comparable results. However, when administered in pharmacological amounts, cortisol acetate and corticosterone acetate and, to a lesser extent, corticosterone were poorly absorbed from the gastrointestinal tract. This was substantiated by measurements of the concentrations of cortisol and corticosterone in the peripheral blood after oral administration of 100 to $200 \mathrm{mg}$ of the acetates, and the free alcohols of these steroids. After the administration of the acetates, only minimal increases of the plasma steroid levels were observed. After oral corticosterone the plasma levels were less than one-third those observed after administration of comparable amounts of cortisol. These lower plasma levels are probably the result of a less efficient absorption and more rapid metabolism of the corticosterone.

By utilizing a double isotope derivative or double isotope dilution assay, some information has been obtained regarding the identity and the quantities of the metabolites of corticosterone comprising the free and conjugated (glucuronide) fractions of the urine. In the normal subject the major $\alpha$-ketolic steroids released after glucuronidase hydrolysis consisted of the tetrahydro $(3 \alpha)$ and allotetrahydro $(3 \alpha)$ metabolites of corticosterone and 11-dehydrocorticosterone. Allotetrahydrocorticosterone was the major metabolite, and the tetrahydrocorticosterone concentration usually exceeded that of 11-dehydrotetrahydrocorticosterone. Other investigators have also reported that the concentration of allotetrahydrocorticosterone exceeds that of other $\alpha$-ketol tetrahydro compounds, and that the level of tetrahydrocorticosterone usually exceeds that of the 11dehydro metabolites (49-52). Pregnane- $3 \alpha, 11 \beta$, $20 \alpha$-triol and $3 \alpha, 11 \beta$,dihydroxypregnane-20-one have also been isolated from the urine of patients treated with large amounts of corticosterone (53). 11-Dehydrocorticosterone has also been isolated from the urines of such patients (52). Normally the predominant metabolite of cortisol is tetrahydrocortisone $(3 \alpha)$, although tetrahydrocortisol $(3 \alpha)$ and its $5 \alpha$ isomer, allotetrahydrocortisol $(3 \alpha)$, appear in measurable quantities (54).

To resolve some of the uncertainties associated with estimations of corticosterone production from determinations of the $\alpha$-ketol tetrahydrometabolites, we have utilized labeled corticosterone to obtain a more quantitative measure of the rate of synthesis of corticosterone. The same two techniques employed for cortisol turnover rates (18, $25,27)$ were found applicable to corticosterone. The corticosterone-4- $\mathrm{C}^{14}$ available to us was, however, not of sufficiently high specific activity $(0.004 \mu \mathrm{c}$ per $\mu \mathrm{g})$ to make possible determinations of the miscible pool size and pool turnover from kinetic measurements of the plasma specific activity of corticosterone-4- $\mathrm{C}^{14}$ after intravenous injection. Subsequent studies demonstrated that these measurements could not be made with anything approaching trace amounts of corticosterone-4-C ${ }^{14}$. For this reason we used $\mathrm{H}^{3}$-labeled corticosterone (1.5 $\mu \mathrm{c}$ per $\mu \mathrm{g}$ ) prepared by the 
Wilzbach technique (55). $\mathrm{H}^{3}$-labeled steroids (17, $26,56,57)$, including cholesterol (58), have been used for tracer studies in human beings and in animals, and there is evidence that the $\mathrm{H}^{3}$ label is sufficiently stable. We have previously published data on the metabolism of simultaneous intravenously administered mixtures of corticosterone4- $\mathrm{C}^{14}$ and randomly labeled corticosterone- $\mathrm{H}^{3}$ (18). In these studies $\mathrm{H}^{3}$-labeled corticosterone and corticosterone-4-C ${ }^{14}$ did not appear to be metabolized differently. On the basis of the studies of Ayres and associates (17) it was indicated that $\mathrm{H}^{3}$-labeled corticosterone $\left(16-\mathrm{H}^{3}\right)$ was metabolized like the parent steroid.

In the normal subjects given rapid infusions of trace quantities ( 7 to $30 \mu \mathrm{g}$ ) of corticosterone- $\mathrm{H}^{3}$, the rapidly exchangeable pool of corticosterone ranged from 0.20 to $0.40 \mathrm{mg}$ with a mean of 0.3 $\mathrm{mg}$. In these same subjects the plasma concentration of corticosterone was 0.8 to $1.5 \mu \mathrm{g}$ per $100 \mathrm{ml}$ with a mean of $1.0 \mu \mathrm{g}$ per $100 \mathrm{ml}$. From the mean plasma corticosterone concentration and the mean corticosterone pool size, it was possible to calculate on "apparent volume of distribution" of this pool. This was calculated to be $30 \mathrm{~L}$. This volume, like that for cortisol $(19,25)$, has no physical reality and must be regarded solely as that theoretical volume required to contain the rapidly exchangeable corticosterone at its concentration in plasma. Following the infusion of 100 mg of unlabeled steroid, a two- to threefold larger volume of distribution was obtained, and this probably results from the fact that a larger fraction of the infused steroid diffused more rapidly into the extravascular space.

Within 8 to 12 hours after the continuous infusion of corticotropin, the miscible pool of corticosterone (and the plasma concentration) showed a four- to tenfold increase. This change in pool size exceeds that previously reported for cortisol after infusion of corticotropin $(18,25)$.

In the normal subjects both before and after the infusion of corticotropin the half-times of the specific activity curves of plasma corticosterone were similar as were the fractional rates of turnover of the miscible pool. However, after corticotropin the hourly rate of turnover of corticosterone was increased four- to tenfold.

With the kinetic method, it was possible to measure the rate of synthesis of corticosterone over a period of only a few hours because the labeled steroid could not be obtained with a sufficiently high specific activity so that a large enough quantity could be used to obtain a measurable yield of radioactivity and yet inject a trace quantity. Also, plasma corticosterone shows a diurnal variation similar to that of cortisol $(13,18)$, and thus the pool would probably not remain sensibly constant for more than a few hours. Studies of cortisol turnover at different times of the day revealed a marked variation in the hourly turnover rate $(18,25)$. By measuring the specific activity of one or more of the urinary radiometabolites of corticosterone, the daily rate of turnover of endogenous corticosterone was determined. With this method it was possible to use the lower specific activity corticosterone-4- $\mathrm{C}^{14}$, since the $200 \mu \mathrm{g}$ injected represented a trace quantity when compared to the total daily production. Results with either corticosterone-4- $\mathrm{C}^{14}$ or corticosterone- $\mathrm{H}^{3}$ were in good agreement. The specific activities of tetrahydrocorticosterone, allotetrahydrocorticosterone and 11-dehydrotetrahydrocorticosterone were comparable, and thus it would appear that each of these metabolites arises solely from a common parent compound (corticosterone). With this technique rates of turnover of 1.3 to $4.0 \mathrm{mg}$ per day were found for normal subjects. When the results of the kinetic method were expressed on the basis of the daily turnover, the data did not agree with the urine specific activity method, and in all instances the former method gave higher values. This undoubtedly indicates that the rate of turnover of corticosterone during the morning hours, at a time when the plasma level of corticosterone is highest (13), is greater than it is at other times of the day. Inaccuracies in the determination of the pool size may also be responsible for appreciable errors in the kinetic assay. Since the corticosterone is metabolized rapidly, prompt dilution of the labeled steroid within the pool, prior to its metabolism, may not occur, and thus the pool size calculations represent only a first approximation. Also, other slower mixing pools may be present and undetected with this type of measurement.

In the studies with corticotropin the turnover rates by the kinetic method, when extrapolated to 24 hours, agreed reasonably well with the results obtained from the urine specific activity method. 
In these instances, however, the miscible pool of corticosterone probably remained reasonably constant. In the bilaterally adrenalectomized subject, the specific activity of the labeled urinary tetrahydrocorticosterone was close to that of the injected labeled corticosterone, indicating no significantly measurable secretion of corticosterone, or other extra-adrenal products metabolized to the tetrahydro metabolites of corticosterone.

In the only other study of corticosterone secretion, Ayres and co-workers (17) reported a daily turnover of $0.84 \mathrm{mg}$ in one normal subject. They measured the dilution of $\mathrm{H}^{3}$-labeled corticosterone by assaying the specific activity of the urinary corticosterone. In two of the subjects of this study the daily turnover rate was calculated by measuring the specific activity of the urinary corticosterone, and a lower secretion rate was found (one-third to one-half that obtained by assay of the tetrahydrometabolites). We also observed this discrepancy between the specific activities of the cortisol and the tetrahydro metabolites of cortisol in normal subjects (18). Cope and Black (27) also observed this difference, i.e., a higher specific activity for the urinary cortisol. It seems probable that these differences may result from the fact that when the steroid is injected rapidly (three to five minutes), it is not well mixed with the body pool prior to excretion, and a larger amount is excreted initially as the free compound.

It is of interest that with both cortisol and corticosterone the fraction of the steroids excreted as the $3 \alpha$ tetrahydro and $3 \alpha$ allotetrahydro metabolites conjugated as glucuronides represented onethird to one-half of the total daily production of the steroids. This was also noted after administration of corticotropin or $100 \mathrm{mg}$ of the steroids. Normally the tetrahydro metabolites of corticosterone are present in the urine in much lower concentrations than the tetrahydro metabolites of cortisol.

Peripheral plasma values of corticosterone have in many instances been reported to approximate or equal those for cortisol (59). This suggested that adrenal corticosterone secretion approached that of cortisol. Bush has reviewed this information (60) and has suggested that the higher plasma corticosterone values previously reported probably resulted from inadequate purification of the steroid prior to analysis. The data on the relative amounts of cortisol to corticosterone in the miscible pool, in the peripheral blood (9-16), and in urine $(13,17)$ support the concept that corticosterone secretion is very much less than that of cortisol and the turnover rate studies confirm this. ${ }^{5}$ Other than the fact that corticosterone is metabolized slightly more rapidly than cortisol, the physiological disposition and metabolic fate of these two steroids are not greatly different.

\section{SUMMARY}

In normal subjects infused corticosterone was shown to disappear from the plasma more rapidly than cortisol. With the administration of large (therapeutic) doses of corticosterone, its rate of disappearance was found to be proportional to concentration. However, trace doses of labeled corticosterone disappeared from the plasma more rapidly than the larger doses. In patients with cirrhosis and myxedema the disappearance of corticosterone from the plasma was only slightly slower than normal, whereas in normal subjects treated with estrogens its disappearance was definitely delayed. In patients with thyrotoxicosis the steroid disappeared from the plasma very rapidly.

Normal subjects within 72 hours excreted 80 to 90 per cent of the administered hormone as urinary and biliary metabolites, as judged by urinary (70 to 80 per cent) and biliary (11 per cent) excretion of $\mathrm{C}^{14}$ - or $\mathrm{H}^{3}$-labeled steroids. Approximately 3 per cent of the administered hormone was excreted unconjugated, and less than 0.5 per cent as unchanged corticosterone. Forty to 60 per cent of the administered dose was excreted as metabolites hydrolyzed with $\beta$-glucuronidase. This fraction consisted predominantly of the tetrahydro and allotetrahydro reduction products of corticosterone. Allotetrahydrocorticosterone was the major tetrahydro metabolite. When administered in pharmacological doses, corticosterone, and especially corticosterone acetate, were found to be poorly absorbed from the gastrointestinal tract.

Utilizing trace quantities of intravenously ad-

${ }^{5}$ Human adrenocortical tissue has also been found to contain less corticosterone than cortisol $(4,61)$. Adrenal cortical tissue slices on incubation produce less corticosterone than cortisol (61). Also, human adrenal vein plasma contains one-fifth to one-tenth as much corticosterone as cortisol (61). 
ministered corticosterone- $\mathrm{H}^{3}$, the miscible pool size of corticosterone was found to be 0.2 to $0.4 \mathrm{mg}$, and the fractional turnover of the pool $0.7 \mathrm{mg}$ per hour. Calculations of the rate of turnover of endogenously synthesized corticosterone, by measurements of the dilution of the specific activity of the urinary tetrahydro metabolites of intravenously administered corticosterone-4-C $\mathrm{C}^{14}$ or corticosterone- $\mathrm{H}^{3}$, indicated a daily rate of production of 1.5 to $4.0 \mathrm{mg}$. Corticotropin increased the rate of synthesis of corticosterone seven- to tenfold.

Although the physiological disposition and metabolic fate of cortisol and corticosterone were not greatly different, the quantity of corticosterone secreted by the adrenal was only one-fifth to onetenth that of cortisol. This results in a lower circulating plasma corticosterone level, and the excretion of a smaller quantity of the tetrahydro metabolites of corticosterone.

\section{ACKNOWLEDGMENT}

We are indebted to Miss Janet Schuck for technical assistance and to the Upjohn, Merck, and Schering Laboratories for generous supplies of steroids.

\section{REFERENCES}

1. Reichstein, T. Über Bestandteile der Nebennierenrinde zur Kenntnis des Cortico-sterons. Helv. Chim. Acta 1937, 20, 953.

2. Mason, H. L., Hoehn, W. M., McKenzie, B. F., and Kendall, E. C. Chemical studies of the suprarenal cortex. III. Structures of compounds A, B, and H. J. biol. Chem. 1937, 120, 719.

3. Bush, I. E. Species differences in adrenocortical secretion. J. Endocr. 1953, 9, 95.

4. Neher, R. Determination of individual adrenocortical steroids. Advanc. clin. Chem. 1958, 1, 127.

5. Hechter, O., Zaffaroni, A., Jacobsen, R. P., Levy, H., Jeanloz, R. W., Schenker, V., and Pincus, G. The nature and biogenesis of the adrenal secretory product. Recent Progr. Hormone Res. 1951, 6, 215.

6. Grant, J. K., Forrest, A. P., and Symington, T. The secretion of cortisol and corticosterone by the human adrenal cortex. Acta endocr. (Kbh.) 1957, 26, 195.

7. Sweat, M. L. Adrenocorticosteroids in peripheral and adrenal venous blood of man. J. clin. Endocr. 1955, 15, 1043.

8. Romanoff, E. B., Hudson, P., and Pincus, G. Isolation of hydrocortisone and corticosterone from human adrenal vein blood. J. clin. Endocr. 1953, 13,1546 .
9. Bush, I. E., and Sandberg, A. A. Adrenocortical hormones in human plasma. J. biol. Chem. 1953, 205, 783.

10. Lewis, B. A paper-chromatographic technique for the determination of plasma corticosteroids. J. clin. Path. 1957, 10, 148.

11. Tamm, J., and Starlinger, H. Zur Bestimmung geringer Mengen Cortisol und Corticosteron mittels Schwefelsäurefluorescenz. Symposium der Deutschen Gesellschaft für Endokrinologie, Berlin, 1956, p. 309.

12. Peterson, R. E. The identification of corticosterone in human plasma and its assay by isotope dilution. J. biol. Chem. 1957, 225, 25.

13. Peterson, R. E. Plasma corticosterone and hydrocortisone levels in man. J. clin. Endocr. 1957, 17, 1150.

14. Bondy, P. K., and Upton, G. V. Simultaneous determination of cortisol and corticosterone in $\mathrm{Hu}$ man plasma by quantitative paper chromatography. Proc. Soc. exp. Biol. (N. Y.) 1957, 94, 585.

15. Takeda, R. A criticism of Sweat's method for the estimation of corticol hormones in plasma. Endocr. jap. 1956, 3, 72.

16. Tamm, J., Beckmann, I., and Voigt, K. D. Über Blutsteroide. II. Papierchromatographische Untersuchungen am peripheren menschlichen Blutplasma. Acta endocr. (Kbh.) 1958, 27, 403.

17. Ayres, P. J., Garrod, O., Tait, S. A. S., Tait, J. F., Walker, G., and Pearlman, W. H. The use of $(16-3 \mathrm{H})$ aldosterone in studies on human peripheral blood. Ciba Found. Coll. Endocr. 1957, 11, 309.

18. Peterson, R. E. The miscible pool and turnover rate of adrenocortical steroids in man. Recent Progr. Hormone Res. 1959, 15, 231.

19. Peterson, R. E., Wyngaarden, J. B., Guerra, S. L., Brodie, B. B., and Bunim, J. J. The physiological disposition and metabolic fate of hydrocortisone in man. J. clin. Invest. 1955, 34, 1779.

20. Peterson, R. E., Pierce, C. E., Wyngaarden, J. B., Bunim, J. J., and Brodie, B. B. The physiological disposition and metabolic fate of cortisone in man. J. clin. Invest. 1957, 36, 1301.

21. Peterson, R. E., Karrer, A., and Guerra, S. L. Evaluation of the Silber-Porter procedure for the determination of plasma hydrocortisone. Analyt. Chem. 1957, 29, 144.

22. Sweat, M. L. Silica gel microcolumn for chromatographic resolution of cortical steroids. Analyt. Chem. 1954, 26, 1964.

23. Bush, I. E. Methods of paper chromatography of steroids applicable to the study of steroids in mammalian blood and tissues. Biochem. J. 1952, 50, 370.

24. Peterson, R. E. The application of tritium to the assay of the steroids in biological extracts. Proc. Symposium on Advances in Tracer Applications 
of Tritium, New England Nuclear Corp., 1958, p. 16.

25. Peterson, R. E., and Wyngaarden, J. B. The miscible pool and turnover rate of hydrocortisone in man. J. clin. Invest. 1956, 35, 552.

26. Pearlman, W. H. (16-3H) Progesterone metabolism in advanced pregnancy and in oophorectomized-hysterectomized women. Biochem. J. 1957, $67,1$.

27. Cope, C. L., and Black, E. G. The behaviour of $\mathrm{C}^{14}$-cortisol and estimation of cortisol production rate in man. Clin. Sci. 1958, 17, 147.

28. Tomkins, G. M. Enzymatic mechanisms of hormone metabolism. I. Oxidation-reduction of the steroid nucleus. Recent Progr. Hormone Res. 1956, 12, 125.

29. McGuire, J. S., Jr., and Tompkins, G. M. The effects of thyroxin administration on the enzymic reduction of $\Delta^{4}$-3-ketosteroids. J. biol. Chem. 1959, 234, 791.

30. Heard, R. D. H., Thompson, L., and Yates, C. A differential method of counting $\mathrm{C}^{\mathbf{1 4}}$ in biological tissues and fluids (abstract). Rev. canad. Biol. 1952, 11, 66 .

31. Southcott, C. M., Sproule, V. A., McIntosh, H., and Darrach, M. Studies on human adrenal steroids. II. Isolation of $20 \alpha$-dihydrocorticosterone from the plasma of normal males treated with corticosterone. Canad. J. Biochem. 1958, 36, 819.

32. Bush, I. E. The physicochemical state of cortisol in blood. Ciba Found. Coll. Endocr. 1955, 11, 263.

33. Daughaday, W. H. Binding of corticosteroids by plasma proteins. III. The binding of corticosteroid and related hormones by human plasma and plasma protein fractions as measured by equilibrium dialysis. J. clin. Invest. 1958, 37, 511.

34. Sandberg, A. A., Slaunwhite, W. R., Jr., and Antoniades, H. N. The binding of steroids and steroid conjugates to human plasma proteins. Recent Progr. Hormone Res. 1957, 13, 209.

35. Slaunwhite, W. R., Jr., and Sandberg, A. A. Transcortin: A corticosteroid-binding protein of plasma. J. clin. Invest. 1959, 38, 384.

36. Upton, V. G., and Bondy, P. K. The binding of cortisol by plasma protein. Arch. Biochem. 1958, 78, 197.

37. Peterson, R. E. The miscible pool and turnover rate of adrenocortical steroids in man as discussed by I. H. Mills. Recent Progr. Hormone Res. 1959, 15, 231.

38. Migeon, C. J., Sandberg, A. A., Paul, A. C., and Samuels, L. T. Metabolism of 4-C $\mathrm{C}^{14}$-corticosterone in man. J. clin. Endocr. 1956, 16, 1291.

39. Brown, H., Willardson, D. G., Samuels, L. T., and Tyler, F. H. 17-Hydroxycorticosteroid metabolism in liver disease. J. clin. Invest. 1954, 33, 1524.

40. Peterson, R. E. Adrenocortical steroid metabolism and adrenal cortical function in liver disease. $\mathrm{J}$. clin. Invest. 1960, 39, 320.
41. Levin, M. E., and Daughaday, W. H. The influence of thyroid on adrenocortical function. $J$. clin. Endocr. 1955, 15, 1499.

42. Peterson, R. E. The influence of the thyroid on adrenal cortical function. J. clin. Invest. 1958, 35, 736.

43. Peterson, R. E., Nokes, G. E., Chen, P. E., and Black, R. L. Estrogens and adrenocortical function. J. clin. Endocr. In press.

44. Sandberg, A. A., and Slaunwhite, W. R., Jr. Transcortin: A corticosteroid-binding protein of plasma. II. Levels in various conditions and the effects of estrogens. J. clin. Invest. 1959, 38, 1290.

45. Hellman, L., Bradlow, H. L., Adesman, J., Fukushima, D. K., Kulp, J. L., and Gallagher, T. F. The fate of hydrocortisone-4-C $\mathrm{C}^{14}$ in man. J. clin. Invest. 1954, 33, 1106.

46. Migeon, C. J., Sandberg, A. A., Decker, H. A., Smith, D. F., Paul, A. C., and Samuels, L. T. Metabolism of 4-C $\mathrm{C}^{14}$-cortisol in man: Body distribution and rates of conjugation. J. clin. Endocr. 1956, 16, 1137.

47. Plager, J. E., Samuels, L. T., Ballard, A., Tyler, F. H., and Hecht, H. H. The rate of metabolism of cortisol in a normal human male. J. clin. Endocr. 1957, 17, 1.

43. Hellman, L., Bradlow, H. L., Frazell, E. L., and Gallagher, T. F. Tracer studies of the absorption and fate of steroid hormones in man. J. clin. Invest. 1956, 35, 1033.

49. Engel, L. L., Carter, P., and Fielding, L. L. Urinary metabolites of administered corticosterone. I. Steroids liberated by glucuronidase hydrolysis. J. biol. Chem. 1955, 213, 99.

50. Romani, J. D. Etude des métabolites urinaires des corticoides chez l'homme; identification des catabolites $\alpha$-cétoliques dan les urines de vingt-quatre heures. C. R. Soc. Biol. (Paris) 1956, 150, 644.

51. Romani, J. D. Etude de l'élimination urinarie des corticoides $\alpha$-cétoliques chez le sujet normal et au cours de la fatigue chronique. II. Fractionnements chromatographiques. C. R. Soc. Biol. (Paris) 1956, 150, 1928.

52. Touchstone, J. C., Bulaschenko, H., Richardson, E. M., and Dohan, F. C. The isolation of corticosterone metabolites from the urine of normal men. Arch. Biochem. 1959, 81, 5.

53. Fukushima, D. K., Kemp, A. D., Schneider, R., Stokem, M. B., and Gallagher, T. F. Studies in steroid metabolism. XXV. Isolation and characterization of new urinary steroids. J. biol. Chem. $1954,210,129$.

54. Bush, I. E., and Willoughby, M. The excretion of allo tetrahydrocortisol in human urine. Biochem. J. 1957, 67, 689.

55. Wilzbach, K. E. Tritium-labeling by exposure of organic compounds to tritium gas. J. Amer. chem. Soc. 1957, 79, 1013.

56. Fukushima, D. K., Bradlow, H. L., Dobriner, K., and Gallagher, T. F. The fate of testosterone in- 
fused intravenously in man. J. biol. Chem. 1954, 206, 863.

57. Gallagher, T. F., Bradlow, H. L., Fukushima, D. K., Beer, C., Kritchevsky, T. H., Stoken, M., 'Eidinoff, M. L., Hellman, L., and Dobriner, K. Studies of metabolites of isotopic steroid hormones in man.. Recent Progr. Hormone Res. 1954, 9, 411.

58. Werbin, H., Bergenstal, D. M., Gould, R. G., and Le Roy, G. V. Evaluation of tritium cholesterol as a tracer in man. J. clin. Endocr. 1957, 17, 337.
59. Ely, R. S., Hughes, E. R., and Kelley, V. C. Studies of adrenal corticosteroids. I. Estimation of plasma corticosterone and cortisol. J. clin. Endocr. 1958, 18, 190.

60. Morris, C. J., and Williams, D. C. Gradient elution chromatography of corticosteroids in human blood, as discussed by I. E. Bush. Ciba Found. Coll. Endocr. 1955, 8, 164.

61. Müller, J., and Peterson, R. E. Unpublished observations. 